\title{
Política educacional pública e sindicalismo docente na Região Metropolitana de Curitiba (PR)
}

\section{Educational public policy and teachers unions in Curitiba (PR) metropolitan area}

\section{Andréa Barbosa Gouveia ${ }^{1}$ Marcos Alexandre Ferraz ${ }^{2}$}

\begin{abstract}
Resumo
As políticas educacionais brasileiras, nos anos 1990 orientaram-se pela descentralização e pela otimização de recursos, princípios, até então, pertinentes às reformas educacionais. Esta perspectiva estava em consonância com a cultura política que dialogava com poderes locais, este encontro ampliou a municipalização do ensino, construiu um modelo de financiamento uniforme e colocou o controle dos recursos na agenda sindical docente. Em um momento de investida de políticas de localização do conflito, a atuação dos servidores nos conselhos de fiscalização de políticas públicas pôde produzir um cenário de invenção democrática. Este artigo avalia a organização dos professores da Região Metropolitana de Curitiba, diante desta agenda. Palavras chaves: Política Pública; Financiamento da educação; Sindicalismo docente.
\end{abstract}

\begin{abstract}
The Brazilian education polices, in the 90', were guided by the decentralization and resource optimization, elements who agree with purposes of education reforms. This perspective met with a politic culture that had talked with significant local politics powers. This encounter increased the learning municipalization, was building a uniform institutional model of financing and was making the social control of education resources in the teaching syndical agenda. In the moment of advance of police by conflict localization, the action of civil servants in councils of public polices fiscalization can produce a scenery of democratic invention. This article is result of research in progress and analyses the organization of teachers in Curitiba Metropolitan Area in front of new agenda.
\end{abstract}

Key words: Public polices; Financing of the education; Teaching syndicalism. 
Este artigo analisa a ação sindical docente na Região Metropolitana de Curitiba, problematizando o embate entre a política educacional municipalizante e a estrutura sindical que tem, também, no município seu espaço de ação. Procuraremos nos desdobramentos deste encontro em relação às possibilidades de ampliação do controle social sobre o uso dos recursos públicos, num período marcado pela secundarização da política, mas contraditoriamente, no campo da educação, com um período de ampliação das possibilidades de intervenção dos sindicatos no acompanhamento das políticas educacionais a partir da participação nos conselhos criados em legislação nacional. Para isto procuraremos localizar o desenho geral da política educacional brasileira, especialmente seus desdobramentos na Região Metropolitana de Curitiba (RMC), em seguida localizaremos o sindicalismo docente na estrutura sindical brasileira; e, finalmente passaremos à análise da ação sindical na RMC.

\section{A política de financiamento da educação no Brasil}

A política educacional brasileira pós Constituição de 1988 tem como traços fundamentais a intensificação da municipalização da oferta de vagas no ensino obrigatório; a ampliação da organização das redes municipais com a constituição de sistemas de ensino; a organização das carreiras do magistério; o intenso debate sobre o papel da União na redução das desigualdades regionais impulsionado pelo mecanismo de redistribuição de recursos em cada estado da federação pela constituição de fundos - primeiro pelo Fundo de Manutenção e Desenvolvimento do Ensino Fundamental e Valorização do Magistério (FUNDEF); e depois pelo Fundo de Manutenção e Desenvolvimento do Ensino Fundamental e Valorização do Magistério (FUNDEB) -; e, finalmente pela ênfase na necessidade de controle social e gestão democrática dos sistemas de ensino impulsionado pela criação de conselhos.

O sistema educacional no Brasil nunca foi plenamente centralizado, os governos locais, com prevalência da esfera estadual, são responsáveis pela educação básica desde o Brasil Império.

Os dados da tabela 1, acerca da matrícula na escola obrigatória, demonstram que até 1995 as redes estaduais e municipais cresceram significativamente, o que se deve a necessidade da universalização do acesso à escola obrigatória. Depois de 1995 há continuidade do incremento de matrículas nas redes municipais, $117 \%$, enquanto nas redes estaduais ocorre um decréscimo de 34\%, o que evidencia uma continuidade da inclusão de alunos nas redes municipais e uma transferência de matrículas estaduais para os municípios.

Tabela 1: Distribuição da Matrícula no Ensino Fundamental - Brasil.

\begin{tabular}{|c|c|c|c|c|}
\hline Ano & Federal & Estadual & Municipal & Privada \\
\hline 1980 & 239.927 & 13.318 .486 & 5.737 .891 & 2.852 .505 \\
\hline 1991 & 96.728 & 16.637 .040 & 8.620 .351 & 3.594 .147 \\
\hline 1995 & 31.330 & 18.347 .733 & 10.491 .098 & 3.798 .579 \\
\hline 1997 & 30.569 & 18.098 .544 & 12.436 .528 & 3.663 .747 \\
\hline 1998 & 29.181 & 17.266 .355 & 15.113 .669 & 3.383 .349 \\
\hline 2005 & 25.728 & 12.145 .494 & 17.986 .570 & 3.376 .769 \\
\hline
\end{tabular}

Fonte: 1980 e 1991: ARAUJO, Gilda (2005); 1995,1998 e

2005: MEC/ INEP Sinopse estatística da educação básica.

O processo de transferência das matrículas da rede estadual para as redes municipais iniciou no Brasil nos anos 70, por força de dispositivos da Lei 5692/71, e, fortemente articulada a procedimentos de reorganização administrativa dos estados (ARELARO, 1999), que nem sempre coincidiam com a capacidade financeira dos municípios, para absorver tal demanda. Isto teve desdobramentos desiguais nas diferentes regiões do país. Em 1991, 46,2\% das matrículas do ensino fundamental pertenciam às escolas municipais na região nordeste, enquanto no sudeste, na entrada dos anos 90, apenas 18,4\% das matriculas obrigatórias estava em redes municipais (CAMARGO et all, 1999).

Na região sul, o processo de municipalização apresentava, no início dos anos 90, uma demanda intermediária das redes municipais que respondiam por $32,5 \%$ da matrícula no ensino fundamental. No estado do Paraná, nas décadas 
de 60 e 70, o processo de municipalização iniciava uma primeira onda, fruto de programas federais voltados, em especial, para a organização da oferta de ensino rural. Na virada dos anos 80 e 90 esse ofertamento intensificara-se por iniciativa do governo estadual devido à precarização das condições de financiamento público para a área da educação como para as demais áreas sociais. Ao longo dos anos 80 , associada à promulgação da Constituição Federal de 1988, que estabelecera uma nova definição tributária, a indicação da prioridade de atendimento escolar pelos municípios, além da fixação de percentuais de receita de tributos a serem aplicados na manutenção e desenvolvimento do ensino, favoreceram o processo de aprofundamento da municipalização do ensino por parte da Secretaria de Estado da Educação (SANTOS, 2001, p.13).

Portanto, no Paraná, quando as políticas de municipalização têm uma nova onda na metade dos anos 90, a rede pública já estava reorganizada e as redes municipais já respondiam, praticamente, por toda a matrícula das séries iniciais do ensino fundamental, como demonstra a tabela 2: em 1985 a matrícula municipal era 32\% da matrícula total, em 1991 quando a participação das redes municipais no Brasil era de 29\%, no Paraná já era de 34\%; em 1997 já era 43\% e chegou a 46\% do total em 2005:

Tabela 2: Distribuição da Matrícula no Ensino Fundamental - Paraná.

\begin{tabular}{|c|c|c|c|c|c|}
\hline Ano & Federal & Estadual & Municipal & Privada & Total \\
\hline 1985 & 1.096 & 909.361 & 501.462 & 148.351 & 1.560 .270 \\
\hline 1991 & 1.161 & 988.398 & 597.618 & 147.659 & 1.734 .836 \\
\hline 1995 & 1.101 & 868.432 & 754.726 & 148.564 & 1.772 .823 \\
\hline 1997 & 1.437 & 870.440 & 780.997 & 139.811 & 1.792 .685 \\
\hline 1998 & 440 & 912.324 & 929.312 & 137.406 & 1.979 .482 \\
\hline 2005 & 476 & 741.430 & 773.843 & 137.780 & 1.653 .529 \\
\hline
\end{tabular}

Fonte: MEC/ INEP Sinopse estatística da educação básica.

A ampliação da descentralização nos anos 90 tem como principal mecanismo a aprovação da Emenda Constitucional №. 14 de 1996, que alterou a política de financiamento da educação. Segundo OLIVEIRA (2003) após a Emenda ainda que 0 ensino fundamental permaneça como competência concorrente de estados e municípios, a nova redação restringe apenas a estes dois níveis da federação a obrigação do atendimento à demanda, desobrigando a União de sua oferta direta, diminuindo a responsabilidade desta na contribuição financeira para com estados e municípios (p. 143).

Aqui se introduz de forma mais incisiva o debate sobre o papel da União na redução das desigualdades regionais, responsabilidade prevista na redação original da Constituição de 1988 e um problema explícito da educação nacional. Para situarmos de forma mais clara - problema da desigualdade na educação brasileira, tomaremos especificamente as regras de financiamento da educação.

A Constituição de 1988 estabelece uma vinculação de recursos para a Manutenção e Desenvolvimento do Ensino (MDE) de 25\% da receita de impostos e transferências de estados e municípios, e de 18\% dos recursos de União. Com a Emenda Constitucional No. 14 houve uma subvinculação obrigatória de $60 \%$ dos recursos de Estados e Municípios para o ensino fundamental e a criação do FUNDEF que alterou a repartição dos recursos dentro de cada estado da federação.

Diversos estudos (DAVIES, 1999; FARENZENA, 2006; OLIVEIRA, 2003) demonstram os impactos das novas regras na expansão da responsabilidade municipal, uma vez que a repartição dos recursos do FUNDEF depende do número de alunos matriculados no ensino fundamental regular. Para entender este efeito é importante perceber o funcionamento do fundo.

O FUNDEF é um fundo de natureza contábil, estadual, que passou a vigorar de forma obrigatória a partir de 1998, com prazo de vigência de 10 anos3. Este fundo reuniu 15\% dos recursos do Imposto sobre Circulação de Mercadorias, Imposto sobre Produtos Industrializados - Exportação, Fundo de Participação dos Municípios, Fundo de Participação dos Estados e recursos da Desoneração de Exportações/ Lei 87/96. A redistribuição dos recursos é feita a partir de um per capita calculado pela razão Desenvolvimento da Educação Básica. 
entre o montante efetivamente arrecadado e o número de alunos matriculados no ensino público fundamental regular do estado.

O papel da União no funcionamento do fundo é suplementar, há um per capita, mínimo nacional, decretado pelo Presidente da República abaixo do qual nenhum fundo pode funcionar. Neste caso, entra a participação da União adicionando recursos do Fundo até o per capita nacional ser atingido. Isto estabelece um mínimo de recursos disponível por aluno no país todo, mas não combate a desigualdade, posto que, os estados com melhor arrecadação têm um fundo maior e, portanto, mais recursos disponíveis por aluno ano, e os estados mais pobres, principalmente no nordeste brasileiro, tem per capita mínimo. Nos 10 anos de vigência do FUNDEF, o per capita nacional variou de $\mathrm{R} \$ 315,00$ (1998) até $R \$ 682,00$ (2006), valores estes que seriam o mínimo gasto por aluno ano matriculado na rede pública. Para dimensionar a desigualdade nacional tomemos como exemplo o ano de 2004. Neste ano, o valor aluno ano realmente realizado foi de $R \$ 541,00$ na Bahia e de $R$ \$ $1.752,00$ em Roraima, o primeiro teve direito a complementação da União até atingir $\mathrm{R} \$ 564,00$. Mesmo com esta suplementação de recursos à desigualdade entre as condições de oferta de ensino nas duas redes se manteve significativa.

Se, em termos de desigualdade entre as regiões do país, os efeitos do FUNDEF são insuficientes, internamente em cada estado da federação há consequências mais substanciais. A forma de gerenciamento dos recursos que redistribui a receita contingenciada no momento da arrecadação resulta que alguns municípios contribuam com mais recursos do que àqueles que recebem de volta do FUNDEF, quando a receita proveniente de tais impostos é grande no município. De outro modo há municípios que recebem mais recursos do que aqueles que ficam retidos no fundo, quando a receita proveniente destes impostos é menor ou quando as redes de ensino são muito grandes. Em decorrência dos recursos recebidos a mais do fundo (ganhar) é que muitas redes municipais ampliaram a matrícula pós FUNDEF.

No caso do estado do Paraná, não há complementação da União, portanto as implicações são apenas de redistribuição de recursos de impostos gerados no próprio estado. Segundo dados disponíveis na Secretaria do Tesouro Nacional, em 2003, por exemplo, dos 399 municípios paranaenses, 189 perdiam recursos com o fundo; os outros municípios recebiam recursos iguais ou maiores do que sua contribuição. Neste caso, o objetivo de equalização das condições de oferta de ensino se realiza no âmbito estadual, ainda que no limite da capacidade fiscal do estado.

Um exemplo disso pode ser vislumbrado mais concretamente em municípios da RMC. A região é marcada por forte desigualdade de condições de arrecadação de tributos, como é usual em regiões metropolitanas que congregam cidades pobres em torno de pólos de desenvolvimento. Os dados apresentados no estudo de Souza e Gouveia (2005) demonstram que, considerando uma amostra de 11 municípios, sem os efeitos do FUNDEF os recursos constitucionais disponíveis por aluno no ano de 2003 variariam de $\mathrm{R} \$$ 562,00 a $R \$ 3.138,00$, entre as cidades aqui consideradas. Com o FUNDEF as diferenças são consideravelmente amenizadas, são 5 vezes o tamanho do per capita do município com mais recursos para o município com menos recursos, que cambiam para um diferencial de 1,9 entre o maior e o menor per capita.

O resultado dessa equalização de recursos entre os municípios de um mesmo estado põe em evidência o financiamento na organização das redes do financiamento na ordem do dia tanto para a reorganização das redes naqueles municípios que têm ganhos com o fundo, quanto para os municípios que têm perdas e que tiveram que redimensionar seus esforços para atender a população. O estudo apresentado neste artigo tem como hipótese inicial de investigação que estas mudanças no financiamento da educação atingiram a ação dos sindicatos na região.

Um dos aspectos importantes do funcionamento do FUNDEF, para a ação dos sindicatos, é a disposição prevista na Lei 9424/96, que obrigou o poder público a aplicar $60 \%$ da receita do fundo no pagamento dos professores em efetivo exercício nas escolas de ensino fundamental. Isto trouxe implicações 
à elaboração de planos de cargos e carreira, assim como, para o acompanhamento das folhas de pagamento, dado à criação de novos abonos em muitos municípios. Isto sem contar com o fato de que se os salários pagos pelos municípios fossem baixos e o total anual aplicado em folha de pagamento não atingisse $60 \%$ dos recursos do FUNDEF, esses recursos não poderiam ser utilizados em outras despesas. Em algumas cidades, isto levou ao pagamento de abonos anuais para os professores. Tal prática criou diferenciação entre salários de professores da mesma rede que atuavam nas classes de educação infantil, sendo fonte de novas desigualdades intraclasse (FITOUSSI e ROSANVALLON, 1996). Assim, a discussão de novos planos de carreira esteve na ordem do dia da década FUNDEF no Brasil.

Outro aspecto importante da legislação, que regulamentou o FUNDEF, foi à instituição de Conselhos de Acompanhamento e Controle Social (CACS). A constituição de tais conselhos é condizente com a preocupação com maior transparência no uso dos recursos públicos, com o princípio constitucional de gestão democrática do ensino público, assim com a ênfase na participação da sociedade na elaboração e na fiscalização de políticas públicas, defendida por diversos setores no processo de redemocratização do país, e que tornou a década de 90 numa época marcada pela criação de conselhos nas mais diversas áreas sociais no Brasil (DOIMO, 1995).

Diferentemente de outros conselhos, os CACS FUNDEF, não têm hierarquia articulada, embora existam conselhos nacional, estaduais e municipais. Os conselhos estaduais e municipais são ligados exclusivamente às respectivas redes estaduais e municipais de ensino e o conselho nacional acompanha apenas as ações da União.

Assim, nos conselhos estaduais os sindicatos docentes tinham representação garantida pela lei 9424/96 que exigia um representante da Confederação Nacional dos Trabalhadores em Educação (CNTE) no Conselho, além de representante de professores que poderia ou não ser indicado pelos sindicatos estaduais a depender da legislação complementar de cada estado.

No caso municipal, os sindicatos não tinham garantia de assento no Conselho, posto que, a lei nacional garantia apenas que os conselhos seriam formados por no mínimo quatro membros que representassem a secretaria da educação, os professores e diretores de escolas públicas, os pais de alunos e os servidores das escolas (BRASIL, 1996, artigo $4^{\circ}$ ). Não havia garantia de que o representante dos professores fosse indicado pela entidade organizada, isto dependia da regulamentação municipal e em grande medida, da intervenção dos sindicatos ao disputar espaços nos conselhos municipais.

Para sustentar a ação dos conselhos, a lei exigia a disponibilização dos registros contábeis e gerenciais relativos ao FUNDEF com o intuito de garantir o acompanhamento efetivo. Entretanto, a literatura acerca do funcionamento do fundo (ARAGÃO, 2003; DAVIES, 1999) demonstrou, ao longo da década, que tal disponibilidade nem sempre se concretizava ou era participativa. Além disso, a própria capacitação dos diferentes segmentos para acompanhar este tipo de documentação nem sempre foi suficiente. Isto levou a organização, pelo Ministério da Educação e pelos Tribunais de Contas dos Estados, de muitos seminários e cursos de capacitação de conselheiros, assim como levou os próprios sindicatos a organizarem espaços de qualificação. No Paraná, a discussão da necessidade de qualificação de conselheiros ligados às entidades dos trabalhadores em educação possibilitou a organização de um Fórum de Conselhos em 2004: espaço articulado pela Secretaria de Professores Municipais do sindicato de professores da rede estadual e por um deputado estadual, organizado para "instrumentalizar e fornecer mecanismos aos conselheiros do FUNDEF para o acompanhamento eficiente da aplicação dos recursos" (FÓRUM, 2004 b).

Ao lado da ação nos conselhos, a lei ainda previa a continuidade e o aprimoramento do controle sobre as contas públicas, realizados pelos próprios Tribunais de Contas e as possibilidades de investigação de problemas via Ministério Público.

Frente a esse conjunto de mudanças, quais sejam, consolidação do processo de municipalização no Paraná; alterações na 
disponibilidade de recursos para educação com certa equalização de gastos; previsão de vinculação de recursos obrigatóriao para pagamento de professores; constituição de espaços de controle social sobre o uso dos recursos do fundo. Toma-se aqui como hipótese que, na última década, tais questões, orientaram parte da política sindical docente, tanto pelo impacto sobre a condição dos trabalhadores em educação, quanto pelo impacto na própria configuração da política educacional municipal e estadual, nas quais os sindicatos buscam intervir.

\section{Sindicalismo e movimento docente público no Brasil}

Para discorrer sobre o sindicalismo brasileiro é preciso, antes, compreender suas características estruturantes. A primeira delas é a forte regulamentação jurídica que pesa sobre as relações entre capital e trabalho no Brasil, desde a sanção da Consolidação das Leis do Trabalho (CLT), estatuída por Getúlio Vargas, e que levou Noronha (1999) a classificar o modelo de regulação do trabalho brasileiro como um modelo legislado, e até Boito Jr. (1991) a denunciar o Sindicalismo de Estado. Independentemente das interpretações que possam ser feitas, cabe registrar, ao menos três componentes desta estrutura: a unicidade sindical, o imposto sindical e o caráter normativo da Justiça do Trabalho.

A unicidade sindical implica em exigência legal para que haja apenas um sindicato de trabalhadores por categoria profissional em determinada região geográfica, sendo o município o limite espacial mínimo. Isto significa que o reconhecimento de um sindicato depende diretamente do Estado e caso, por definições políticas e/ou ideológicas não atenda aos interesses dos trabalhadores, estes estão impedidos de organizar outro que venha representá-los. Também significa que com bases municipais, há uma proliferação de pequenos sindicatos com baixo número de trabalhadores em suas respectivas bases, pulverizando a ação sindical (ALMEIDA, 1996).

O imposto sindical é uma contribuição compulsória, equivalente a um dia de trabalho por ano, que todo trabalhador, independente de ser sindicalizado, oferece ao sistema sindical brasileiro. Esta cobrança é feita diretamente em folha de pagamento, repassado ao Estado que o divide entre Sindicato, Federação, Confederação e Ministério do Trabalho. Tal fonte de recursos possibilita uma desvinculação entre representação política e/ou jurídica e organização e/ou sindicalização dos trabalhadores. Junte-se a esta independência financeira, o fato de um trabalhador, no modelo brasileiro, ser coberto por um acordo coletivo de sua categoria independente de sua filiação. Em outras palavras, é possível um sindicato com baixo percentual de sindicalização transformar-se em forte ator político, pois o poder sindical não se mede apenas pelas taxas de filiação, mas pelo seu poder de realizar ou impedir mobilizações coletivas (CARDOSO, 2003). Poderíamos acrescentar também, pela capacidade de influenciar a opinião pública (FERRAZ, 2000).

Por fim, o poder normativo da Justiça do Trabalho impõe que a resolução de um impasse nos conflitos entre capital e trabalho possa ser resolvida através de um ato jurídico, independente das respectivas forças sociais dos litigantes. Isso contribuiu para um fenômeno que se tornou típico no Brasil e alguns autores chamaram de processo de judicialização das relações de classe (VIANNA, 1999; CARDOSO, 2003). Tal acontecimento consiste na predominância de soluções individuais de direito, sobre a negociação coletiva dos conflitos. Novamente impulsionando a fragmentação da ação.

Este conjunto de características estruturais moldou objetivos e criou estratégias sindicais, que a partir dos sindicatos de categorias profissionais e municipais, buscaram maximizar os ganhos de seus representados, independente de possíveis efeitos agregados (ALMEIDA, 1996). Mesmo com a legalização das Centrais Sindicais, a partir da Constituição de 1988, estas se constituíram apenas como núcleo político identitários, sem poder de representação legal, permanecendo à pulverização e municipalização da ação sindical (CARDOSO, 1992; COMIN, 1995). Do ponto de vista, exclusivamente legal, este quadro estrutural não pesa sobre o sindicalismo docente público, visto que, como será detalhado 
adiante, o sindicalismo de servidores públicos não é regulado pela CLT. Entretanto, não se pode menosprezar a força de uma cultura sindical, que foi desenhada por essa estrutura ao longo de mais de 70 anos, sobre o sindicalismo docente público que nasce entre os anos 1970 e 1980. Pois esta estrutura, ainda que moldada para o setor privado das relações de trabalho potencializou, inclusive, entre os servidores públicos, o processo que Oliveira (1998), ao discutir o Fundo Público como um elemento estrutural da reprodução social do capitalismo, registrou como a transferência do palco central do conflito entre capital e trabalho do chão da fábrica e dos demais espaços de trabalho para o interior do Estado4. Essa transferência se fará, principalmente, ao redor das disputas por políticas públicas, e poderemos observar como as definições legais sobre o financiamento da educação, mais especificamente a vinculação de $60 \%$ dos recursos do FUNDEF à folha de pagamento, impulsionaram algumas ações sindicais docentes. Mas antes, é preciso localizar o sindicalismo docente público brasileiro.

Até a Constituição de 1988, a organização sindical dos servidores públicos era proibida no Brasil. Isso não significa que não existiam formas alternativas de organização de interesses entre os docentes públicos, assim como entre outros servidores brasileiros. No entanto, a proibição da representação propriamente trabalhista impulsionou a organização dos servidores em associações de caráter, sobretudo corporativa e assistencial (NOGUEIRA, 2005). Ainda assim, entidades como a ABE - Associação Brasileira dos Educadores-, criada em 1924, desempenhou importante papel político e pedagógico, mas sem pretensões sindicais (GADOTTI, 1996); destacase também a ação da CPPB - Confederação dos Professores Primários do Brasil, fundada em 1960 que, a partir de 1978, passaria a se chamar CPB - Confederação dos Professores do Brasil (GADOTTI, 1996).

As mobilizações sociais do fim dos anos 1970, que colocaram fim a ditadura militar e

4 A transferência do conflito para o interior do Estado, no sentido dado por Oliveira (1998), não deve ser confundido com o fenômeno do sindicalismo de Estado. Para uma crítica sobre a cooptação do movimento sindical pelas estruturas de Estado, ver: BOITO JR, 1991. restabeleceram a democracia no país, foram fundamentais para dinamizar a ação coletiva e sindical entre os docentes. Em 1978, em consonância com o Novo Sindicalismo, os professores das redes estaduais de São Paulo, Brasília e Paraná realizaram greves com adesão altíssimas das respectivas categorias. Tais greves não atingiram resultados econômicos significativos, mas tiveram importância política.

A greve de São Paulo, por exemplo, contou com o apoio de cerca de $80 \%$ da categoria (NOGUEIRA, 2005), e, assim como a dos demais estados, foi organizada por um comando de greve independente das associações de professores existentes. Este movimento de base, com forte adesão, proporcionou a construção de novas lideranças que, pouco a pouco, disputaram e conquistaram as principais associações de professores do país. No ano seguinte, 1979, as greves e o aparecimento de novas lideranças se repetiram, mas desta vez com estados como Rio de Janeiro, Rio Grande do Sul e Minas Gerais. Após a Constituição de 1988, estas associações seriam transformadas em sindicatos. $O$ mesmo movimento que politizou e mobilizou as associações estaduais transformou a atuação da CPB, que a partir de 1989, já com uma nova linha política e ideológica, transformou-se na CNTE Confederação Nacional dos Trabalhadores em Educação.

O diálogo contínuo com as principais lideranças do Novo Sindicalismo propiciou algumas características neste movimento organizativo dos professores, dentre elas: 1) A heterogeneidade de matrizes-discursivas composta pelos sindicalistas autênticos, militantes católicos e militantes de esquerda, em especial leninistas e trotskistas (SADER, 1988); 2) Rejeição a exploração capitalista e à matriz comunista autoritária (SADER, 1988; COMIN, 1995); 3) Posicionamento crítico frente à estrutura sindical corporativa e a intervenção estatal nas relações entre capital e trabalho, concomitantemente a uma aposta na disputa pelos espaços institucionais que esta mesma estrutura proporcionava (ALMEIDA, 1996; COMIN, 1995; VÉRAS DE OLIVEIRA, 2002); 4) Valorização da democracia expressa na luta pelo fim do autoritarismo, nos esforços para a organização do 
movimento sindical e na prática de mobilização da base (VÉRAS DE OLIVEIRA, 2002).

Dentre essas características precisamos compreender de forma satisfatória a dimensão sociológica desta valorização da democracia. Sob a égide weberiana, podemos salientar que no universo ideológico Novo Sindicalismo, a preocupação com a democracia deve ser interpretada como um valor que orienta a ação sindical (FERRAZ, 2005). O que precisamos demarcar é que, já em seu nascimento, a despeito de todas as tensões internas, a opção por avançar a luta dos trabalhadores, no nosso caso especificamente dos docentes, dentro das regras democráticas já estava sendo feita. A consequência sociológica desta opção é que para os trabalhadores fazerem uso das oportunidades oferecidas pela democracia, a participação tornase imperativa (PRZEWORSKI, 1989).

Assim, independentemente dos novos marcos legais que a Emenda Constitucional $N^{\circ}$. 14 instituiu, o movimento docente, já na origem, apontava para políticas participativas no interior do próprio Estado. Ou como Monlevade descreve no período pós-1987, como um momento no qual os professores se tornam produtores e defensores de propostas (MONLEVADE, 1990). Tal movimento pode ser verificado na atuação das associações e sindicatos de professores na formulação do capítulo da educação da Constituição de 1988, da Lei de Diretrizes e Bases da Educação Nacional (LDB), aprovada em 1996, e na posterior participação nos CACS criados no âmbito do FUNDEF, objeto maior deste artigo. Ridentti (2006), falando do conjunto do sindicalismo brasileiro, sugere a expressão Institucional Defensivo para caracterizar este padrão de ação.

Esta atuação constante, não está apenas na defesa dos interesses corporativos, característica estrutural de qualquer sindicato de trabalhadores, mas também na formulação das políticas, assim como na defesa de sua efetividade junto à população, que pode, até mesmo, se constituir como hipótese explicativa para uma questão aludida por Cardoso (2003). Qual seja: o crescimento da ação sindical de servidores públicos, ao longo dos anos 90, mesmo diante de um cenário defensivo e liberal que caracterizou o período e reduziu muito o protagonismo dos sindicatos de trabalhadores no setor privado. Ante ao recuo das filiações sindicais - tanto da área privada como das estatais privatizadas - e, mesmo a despeito dos processos de sucateamento dos serviços públicos, a maioria dos sindicatos de servidores públicos conseguiu ampliar suas bases.

A importância política do sindicalismo docente ao longo dos anos 90 pode ser, inclusive, aferida pela evolução das taxas de sindicalização. Entre 1988 e 1998, em todo do setor de ensino, o número de empregos aumentou em 750 mil. Os sindicatos do setor não apenas filiaram percentuais significativos destes novos trabalhadores, como ampliaram em 8 pontos percentuais de sua densidade sindical (CARDOSO, 2003, p. 234). Tal comportamento mostra certa eficiência na ação sindical, ao menos no processo de adesão de novos trabalhadores. No mesmo período, sindicatos tradicionais, como metalúrgicos e bancários, experimentaram o caminho inverso não apenas pela eliminação de milhares de postos de trabalhos junto a suas categorias, como experimentaram taxas significativas de queda em suas densidades sindicais: - 8 pontos para metalúrgicos e - 3 pontos para bancários (CARDOSO, 2003, p. 234).

Assim, para analisarmos, na sequência abaixo, alguns casos concretos de sindicatos de professores da RMC, consideraremos a vivencia cultural e estrutural dos anos de expansão das bases e do poder de intervenção social dos sindicatos, para depois buscar indicadores de ação democrática, assistindo-os como um interlocutor legítimo e não apenas como um representante oponente de classe, herdeiro de um sindicalismo desenvolvido no interior de uma estrutura sindical altamente legislada, municipalizada, e cuja legitimidade social, enquanto ator social dirigente sindical pode, muitas vezes, não estabelecer mediação com a base de trabalhadores da categoria. É com a ação dos sindicatos docentes que o movimento de municipalização de ensino, ampliado pelas políticas de financiamento da educação que analisaremos nas próximas páginas, um caso empírico ocorrido na Região Metropolitana de Curitiba. 


\section{Ação sindical docente na região metropolitana de Curitiba}

A RMC é formada por 26 municípios, e apresenta o nono maior PIB do país e contém $31 \%$ da população paranaense. Todos os municípios possuem redes próprias de ensino fundamental e de educação infantil, nos termos da divisão de responsabilidades prevista na Constituição Federal. Em todos os municípios há Secretarias Municipais de Educação. Entretanto, não são todos os que contam com entidades de organização dos trabalhadores em educação. Nos municípios que têm movimento organizado, este pode se dar por meio de um sindicato próprio (casos de Curitiba, Araucária, Campo Largo, São José dos Pinhais e Lapa), ou em associações municipais filiadas ao sindicato estadual de professores (casos de Colombo, Piraquara e Fazenda Rio Grande).

Este artigo apresenta o resultado da primeira fase da pesquisa sobre a ação sindical docente frente às mudanças na política de financiamento da educação no Brasil pós 1990. Tomaremos para análise entrevistas com representantes das quatro entidades representativas de professores: Sindicato dos Servidores do Magistério Municipal de Curitiba (SISMMAC), Sindicato dos Servidores do Magistério Municipal de Araucária (SISMMAR), Associação dos Professores do Município de Colombo (APMC) e APP- Sindicato dos Trabalhadores em Educação do Paraná (APP)5. As três entidades sindicais municipais representam cerca de 9.200 professores6, sendo 6.885 em Curitiba, 1.287 em Colombo e 1.058 em Araucária. Já o sindicato estadual tem como base 84.000 professores.

Em termos de densidade de representação sindical cabe destacar o nível de sindicalização estadual e da capital, que congrega a maior parte

5 A APP-Sindicato é um sindicato de base estadual que representa os trabalhadores em educação da rede de ensino. Na ausência de sindicatos municipais em diversas cidades do Estado, a APP- Sindicato atua conjuntamente às Associações Municipais de Professores. Este é o caso de Colombo. Uma disputa pela representação legal com estas associações provavelmente resultaria em uma derrota para APP-Sindicato.

6 Dados sobre funções docentes em atuação nas redes de ensino segundo Censo Escolar de 2006 (INEP/MEC), como os dados são sobre funções docentes pode haver redução das quantidades quando o mesmo indivíduo ocupa duas funções docentes. dos docentes na RMC. A tabela 3 apresenta o perfil de sindicalização nos últimos 5 anos:

Tabela 3: Número de sindicalizados e total de funções docentes em dois grandes sindicatos da RMC, 2003-2008.

\begin{tabular}{|c|c|c|c|c|c|}
\hline \multirow{3}{*}{ Ano } & \multicolumn{5}{|c|}{ APP sindicato (rede estadual) } \\
\hline & \multicolumn{3}{|c|}{ Sindicalizados } & \multirow{2}{*}{$\begin{array}{l}\text { Total de } \\
\text { funções } \\
\text { docentes }\end{array}$} & \multirow{2}{*}{$\begin{array}{c}\% \\
\text { Sindica- } \\
\text { lizados }\end{array}$} \\
\hline & Total & Ativa & Aposentados & & \\
\hline 2003 & 48.829 & 26.863 & 21.966 & 75.614 & 64,6 \\
\hline 2004 & 52.052 & 29.817 & 2.235 & 75.844 & 68,6 \\
\hline 2005 & 54.992 & 32.368 & 22.624 & 75.034 & 73,3 \\
\hline 2006 & 52.227 & 29.765 & 22.462 & 81.719 & 63,9 \\
\hline 2007 & 52.926 & 30.547 & 22.379 & \multirow{3}{*}{\multicolumn{2}{|c|}{ Sem informação }} \\
\hline 2008 & 50.681 & 28.375 & 22.306 & & \\
\hline Cresc & 3,8 & 5,6 & 1,5 & & \\
\hline \multirow{3}{*}{ Ano } & \multicolumn{5}{|c|}{ SISMMAC Curitiba (rede municipal) } \\
\hline & \multicolumn{3}{|c|}{ Sindicalizados } & Total de & $\%$ \\
\hline & Total & Ativa & Aposentados & $\begin{array}{l}\text { funções } \\
\text { docentes }\end{array}$ & $\begin{array}{l}\text { Sindica- } \\
\text { lizados }\end{array}$ \\
\hline 2003 & 3.763 & 2.954 & 809 & 6.254 & 60,2 \\
\hline 2004 & 3.240 & 2.445 & 795 & 6.570 & 49,3 \\
\hline 2005 & 4.175 & 3.279 & 896 & 6.615 & 63,1 \\
\hline 2006 & 4.284 & 3.309 & 975 & 7.162 & 59,8 \\
\hline 2007 & 4.557 & 3.430 & 1.127 & \multirow{3}{*}{\multicolumn{2}{|c|}{ Sem informação }} \\
\hline 2008 & 4.583 & 3.359 & 1.224 & & \\
\hline Cresc & 21,8 & 13,7 & 51,3 & & \\
\hline
\end{tabular}

Fonte: dados da sindicalização - APP sindicato; SISMMAC. (dados tabulados pelos autores); funções docentes - INEP/MEC.

As informações acerca destes dois sindicatos permitem observar o crescimento no total de filiados no período, sendo que o sindicato municipal cresceu mais e se manteve até o fim do período; no caso do sindicato estadual há certa flutuação na filiação, apesar de haver um crescimento de 3,8\% quando comparado 2008/2003, há uma perda de $8 \%$ filiações pós 2005.

Nas duas redes - estadual para o conjunto do Paraná e municipal para Curitiba - há incremento de postos de trabalho para docentes, e elevação nas funções docentes entre 2003 e 2006 da ordem de $8 \%$ na rede estadual e de $14 \%$ na rede municipal de Curitiba. Com o aumento do número de funções docentes, o percentual de filiação se manteve acima dos 60\% no sindicato estadual e acima dos 50\% no sindicato municipal, com exceção do ano de 2004. Esta comparação, entre número de filiados e funções docente, permite ter uma indicação inicial da representatividade da 
categoria. Porém, o percentual pode ser maior se considerarmos que um mesmo professor pode ocupar duas funções docentes e se sindicalizará apenas uma vez.

A prova da diferenciação entre a dinâmica de sindicalização nos dois casos, pode estar na composição de sindicalizados ativos e aposentados. Neste sentido, o percentual de sindicalizados aposentados tem aumentado, porém isto é muito maior na rede municipal. Entretanto, quando comparamos o percentual de sindicalizados na ativa, mesmo com o incremento de aposentados na entidade municipal, o percentual de filiados na base tende a ser maior no município.

\section{Gráfico 1: Percentual de sindicalizados na ativa frente as funções docentes.}

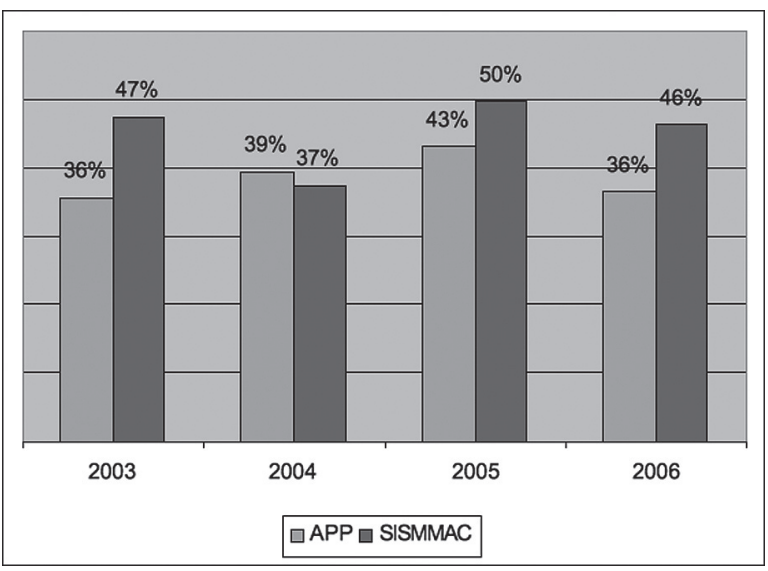

Fonte: dados sindicalização - APP sindicato; SISMMAC. (dados tabulados pelos autores); funções docentes - INEP/MEC.

Esta caracterização mais longa dos dois maiores sindicatos na RMC pretende explicitar em termos quantitativos a dinâmica positiva destas entidades na região, de forma a podermos avançar nos dados qualitativos preliminares, resultado das entrevistas com os dirigentes.

\section{A ação sindical e o financiamento da educação}

Entre os municípios considerados neste artigo, temos situações em relação ao FUNDEF bastante heterogêneas, enquanto Colombo, segundo os dados de 2003, tem seu valor aluno ano disponível acrescido em mais de 100\%, em Araucária vive a situação oposta com um decréscimo de recursos na ordem de $30 \%$. Curitiba, capital do Estado e município central da RMC, tem uma situação bastante confortável frente ao FUNDEF, sem os recursos do fundo a cidade tem o segundo per capita por aluno na região, com o fundo este recursos têm um acréscimo de 18\%.

A questão da redistribuição dos recursos entre os municípios parece ser um grande complicador da ação sindical, sobretudo quando a cidade perde recursos. Isto é explicitado na avaliação do representante do SISMMAR:

A gente tinha clareza disto [perdas do município para o FUNDEF], mas sindicalmente para você trabalhar que é este o problema, parece que você está jogando contra a categoria, parece que você está tirando do prefeito à responsabilidade pela precarização. E também, por outro lado os administradores utilizam este discurso para dificultar a negociação. (entrevista representante do SISMMAR)

Quando o município recebe do FUNDEF recursos a mais, a interpretação das possibilidades disto são, também, disputadas com as administrações, segundo relato da representante da APMC. O incremento de receita era avaliado como insuficiente pela administração municipal:

A gente acompanha e sabe que há ganhos. A Secretaria da Fazenda não confirma isto, eles dizem que estão perdendo e que com 0 FUNDEB perderão mais. Mas, assim, ganham no sentido que ela contribui com uma parte e o que recebe é maior, ganho em relação a isto. A Fazenda acha que o município deveria receber mais recursos. (...) (entrevista representante da APMC)

Exigiu-se dos sindicatos para organizar e acompanhar esta dinâmica e discutir com as administrações, com o intuito de compreender os meandros dos orçamentos num processo de apropriação do conhecimento específico das questões acerca do financiamento da educação. Isto é destacado pelos representantes de Curitiba e Colombo:

Nós começamos em 2002, até aí nós não tivemos na associação nenhum trabalho que tivesse relação com o financiamento da educação. Nós tivemos em abril de 2002 um encontro [...]. Começamos aí a discussão, levantar toda a problemática do financiamento. Para você entender a importância que isto tem, para que você possa estar brigando por melhores condições de trabalho, melhores salários, você tem que entender da parte financeira senão você não consegue. (entrevista representante da APMC, 2007). 
Acho que tem toda a diferença [ação sindical antes e depois do FUNDEF][...]. Tanto no sentido de você se organizar e ter a preocupação de qualificar aquelas propostas. Quando a gente ia discutir as cláusulas econômicas, antes a gente era meio espectador do DIEESE. 0 DIEESE dizia, gasta tanto com pessoal e pode gastar tanto, e a gente ia em cima daquele tanto... Teve um crescimento na entidade, no sentido que o DIEESE dizia isto, mas a gente queria outras informações. Gasta tanto com pessoal, quanto que sobra para as outras coisas. (entrevista representante do SISMMAC, 2007).

A avaliação do representante do SISMMAR é que a preocupação com a qualificação das condições de negociação pela compreensão do orçamento público no caso de Araucária precede a implantação do FUNDEF, segundo ele:

Isto era uma visão própria minha e de outras pessoas, inclusive antes do FUNDEF a gente já tinha esta preocupação, é aquela lógica de você saber em cima do que está negociando. Vai um pouco pela questão do sindicalismo de resultados, mas você tem que aliar a luta por melhores condições de trabalho em cima de possibilidades de financiamento. E a discussão do FUNDEF sempre nos preocupou muito mais do que auxiliou (entrevista representante do SISMMAR, 2007).

A busca pela melhor negociação, tendo com o FUNDEF como desencadeador ou não desta questão, colocou, nos últimos anos, na pauta sindical, o debate sobre as finanças públicas e uma preocupação com uma visão de conjunto sobre a ação do Estado no atendimento à população. Os dirigentes entrevistados indicam isto como superação de uma perspectiva meramente corporativa, tanto em termos de ampliação do debate acerca do investimento em outras políticas públicas, quanto em relação à necessidade de investimento em educação. Não se restringindo às melhorias salariais, mas a qualidade do ensino ofertado que implica em: condições de trabalho, formação continuada e atendimento às crianças nas redes de ensino.

Ainda que as entrevistas indiquem a existência da preocupação da política educacional como política pública, como uma construção que não se fez apenas a partir do FUNDEF, a participação no Conselho do FUNDEF e, no mesmo período, em outros conselhos de políticas públicas, reforça tais temáticas no interior das instâncias sindicais.
Quanto à participação no Conselho do FUNDEF, em Araucária a constituição do conselho incorporou desde o começo a participação do sindicato, mesmo que a Lei Municipal apenas reproduza o estabelecido na norma nacional, isto foi garantido desde a primeira gestão do conselho. Nos casos de Curitiba e de Colombo o processo foi mais complicado. Na capital, além das intervenções na tramitação da lei, nas quais não houve muitos avanços, o sindicato incluiu na negociação, na data base seguinte à criação do conselho, a indicação do representante dos professores pela entidade:

Nós começamos a debater quando foi 0 projeto de lei para Câmara Municipal, criando o conselho do FUNDEF. Na época a gente fez uma discussão e apresentou emendas tanto na composição como a forma de indicação do presidente, porque o presidente era o próprio representante da secretaria. As emendas não passaram, mas aí a gente conseguiu garantir que 0 representante do magistério fosse do SISMMAC. Isto nas negociações, porque na própria lei isto não estava. Estava apenas o representante dos professores. (entrevista representante do SISMMAC, 2007).

Depois desta negociação, o representante passou a ser eleito em assembléia da categoria e indicado pela entidade sindical. Em Colombo, a entrada da associação no Conselho de forma institucional também não estava prevista em lei e foi garantida nas negociações coordenadas pela diretoria eleita em 2002. Antes disto a Secretaria de Educação indicava os representantes dos professores a partir de uma consulta feita via questionário enviado às escolas:

... este debate veio depois [debate sobre participar do conselho do FUNDEF] que a gente assumiu a associação, depois da discussão com a APP. Nós já questionamos na primeira reunião em janeiro de 2002. Em meados de setembro eles já mandaram um documento solicitando que a gente indicasse uma pessoa. Isto já foi uma conquista. Aí nós fizemos uma assembléia e indicamos a pessoa. (entrevista representante da APMC, 2007).

No caso da entidade estadual o processo é mais simples dado que a legislação nacional é explícita na indicação de um representante da Seccional da CNTE no Conselho. Além deste representante, está previsto outro representante dos professores. No caso do Conselho Estadual 
de Acompanhamento e Controle Social do Paraná (CONFEMA) há um representante da APP, portanto os professores têm duas vagas no âmbito do estado. Um dos representantes da APP foi, desde a implantação do conselho, o diretor da Secretaria de Municipais da entidade. Esta Secretaria acabou sendo o espaço organizado de debates sobre os conselhos e a questão do financiamento da educação no sindicato estadual, estando previsto este acompanhamento na descrição das áreas de atuação da Secretaria na organização sindical:

Secretaria de Municipais exerce um importante papel nessa área, como assessoria aos participantes dos conselhos, ajuda a acompanhar e controlar a repartição, transferência e aplicação dos recursos do FUNDEF. Através de palestras e seminários, tem ajudado na capacitação da comunidade quanto ao controle público do uso desses recursos. (APP sindicato, 2007)

Esta preocupação com a assessoria dos municípios é destacada pelo dirigente da Secretaria de Municipais:

Através da secretaria de municipais da APP mais diretamente com os municípios sindicalizados diretamente e em colaboração com outros que têm dúvidas. Qual é o trabalho que a gente faz? Instrumentalizar, tentar indicar 0 que fazer para eles que, é incrível. Está acabando o FUNDEF e o pessoal ainda não sabe os caminhos para a fiscalização, que documentos acessar e tudo, desde elaboração de requerimento e ofício até prestação de contas e reuniões para formação, palestras, tudo isto a gente faz. (entrevista com representante da APP, 2006).

A criação de uma Secretaria de Municipais na entidade estadual e o fortalecimento da ação dos sindicatos municipais independentes parece relacionar-se, diretamente, ao movimento de municipalização sendo um dos aspectos da reorganização das redes municipais. Ainda que os entrevistados até aqui não associem tal movimento de fortalecimento do debate municipal à política de financiamento dos anos 90, que priorizou a instância local, a movimentação constatada empiricamente, neste âmbito, parece exigir maior aprofundamento da pesquisa para dimensionar os meandros deste processo.

Dado a incorporação direta ou negociada dos sindicatos aos conselhos do FUNDEF, cabe ponderar como se construiu a relação entre os representantes dos professores nos conselhos e a entidade sindical. Os entrevistados, em geral, indicaram os espaços de assembléia, conselhos de representantes de escola e jornais das entidades como aqueles em que as notícias do conselho eram divulgadas para a categoria. Ainda assim os dirigentes entendem que tal articulação era relativamente frágil:

Nós fazíamos um retorno na reunião de representantes, sempre tinha 0 representante na reunião e procurava passar a informações. Eu ainda acho muito precário. Os nossos professores querem resolver seus problemas financeiros do ponto de vista deles. Eles não querem saber como é que isto acontece, não estão preocupados em se organizar e ir buscar junto. (entrevista representante da APMC, 2007).

A ideia era que houvesse um debate mais coletivo, mas isto nem sempre acontecia, pela própria dinâmica do sindicato, mas a gente tinha um acompanhamento de um assessor técnico que era um contador. (entrevista representante do SISMMAC, 2007).

Não se pode dizer que a categoria tinha clareza da importância desta participação, mas a diretoria do sindicato tinha a clareza da importância. (entrevista representante do SISMMAR, 2007).

Mesmo com o suporte dos sindicatos, seja pela via da contratação de contadores, para auxiliar, seja pela discussão em seminários e similares, a ação dos representantes nos conselhos enfrentou vários problemas quanto ao acesso à documentação e, quanto ao fato dos professores serem minoria nos conselhos, e também por inexperiência com o tipo de discussão, que seria pertinente naquele espaço. Ainda assim, os dirigentes entrevistados destacam pelo menos dois pontos importantes da intervenção de seus representantes junto aos CACS:

1) A fiscalização da folha de pagamento, que mesmo com dificuldades no acesso aos documentos, possibilitou, em muitos casos, identificar servidores que estavam equivocadamente sendo pagos com esta fonte de recursos:

Houve uma série de coisas que 0 conselho organizou. Araucária com a obrigatoriedade dos 25\% para educação, a educação tem um orçamento muito perto de municípios de médio porte, hoje são perto de 80 milhões anuais. Então, 80 milhões por ano, dá para você desovar muita coisa por ali. [...] Uma das primeiras 
coisas que o conselho fez foi organizar os recursos do FUNDEF para pagar só professores que estão atuando em sala de aula. E isto a gente pegou porque nossos representantes no conselho pegavam os relatórios e traziam para o sindicato e assim a gente acompanhava, eu, por exemplo, era dirigente sindical, liberado da sala de aula e recebia pelo FUNDEF, então a gente fez toda uma checagem e aí foram criados vários centros de custo na SME. (entrevista representante do SISMMAR, 2007).

Nas vezes que tivemos acesso a documentação - que eles davam correndo na reunião -, encontramos, por exemplo, pessoas que estavam atuando na educação infantil na conta do FUNDEF. Aí fizemos uma lista e passamos para os conselheiros do FUNDEF e eles procuravam aqueles nomes e achamos algumas pessoas desta forma. E a gente solicitou a reversão. (entrevista representante da APMC, 2007).

A gente teve acesso a informações que a gente não tinha antes, por exemplo, quantas pessoas efetivamente estavam na escola atuando, quantas pessoas estavam cedidas a outras Secretarias ou na Secretaria da Educação. Porque tinha toda a discussão do pagamento de 60\% do FUNDEF que deveria ser pago para quem estivesse atuando em escolas. (entrevista representante do SISMMAC, 2007).

2) A garantia de que o Dirigente Municipal de Educação não fosse o presidente do conselho, posto que se constitui como executor da política: E daí a gente começou a interferir diretamente na gestão naquele momento, pois, quem presidia 0 conselho do FUNDEF era a Secretaria de Educação. Então a primeira coisa que a gente fez foi questionar isto. Nós tivemos uma audiência com a prefeita e a gente pontuou isto, porque do ponto de vista legal não tinha problema porque a lei não dizia que não podia. Mas do pondo de vista moral era ela que assinava o cheque e ela mesmo fiscalizava. (entrevista representante da APMC, 2007).

Considerando a falta de transparência no uso dos recursos públicos e o fato de que em educação as pesquisas nacionais (VERHINE, 2006) comprovam que o maior custo está na folha de pagamento, os sindicatos conseguiram intervir timidamente devido a esse contexto, mas não de maneira insignificante.

Neste mesmo período outras discussões ocuparam a pauta sindical e tinham forte relação com a compreensão do orçamento público. Planos de carreira para professores e educadores, reforma na previdência dos servidores públicos e instituição de Fundos de
Previdência nos municípios foram pauta sindical nos três municípios. Todos os entrevistados destacaram esses debates, assim como a criação de conselhos ligados aos Institutos Municipais de Previdência. A interconexão entre tal pauta e a política nacional de financiamento da educação ainda está por ser analisada.

\section{Considerações finais}

Mais do que tecer considerações finais, procuraremos estabelecer algumas questões que valem ser investigadas em trabalhos futuros. Para isso vamos recuperar alguns pressupostos que havíamos enumerado na segunda parte deste mesmo texto. Em primeiro lugar os anos 1990 foram anos de ampliação da base de trabalhadores docente, assim como de suas taxas de filiação (CARDOSO, 2003). Isso significa que a participação nos CACS pode representar um avanço no movimento sindical docente público sobre novas arenas políticas, e não, necessariamente, um recuo defensivo frente ao processo de sucateamento dos serviços públicos e de precarização das condições de trabalho. Os dados dos quais dispomos são insuficientes, no momento, para contradizer uma ampla literatura que tenta demonstrar a tese sobre o retrocesso sindical, também entre os docentes, ao longo da última década do século XX. Entretanto, temos elementos suficientes para relativizá-la, assim como para suscitar investigações mais complexas sobre o movimento docente.

No entanto, se a ação nos Conselhos, pode ser caracterizada como um sindicalismo em ascensão que busca novos espaços políticos, ela o faz reforçando algumas tendências. A cultura sindical brasileira, essencialmente municipalista encontra a política de municipalização do financiamento da educação em movimentos que parecem se reforçar mutuamente. Se nos casos de Curitiba e de Araucária, os Sindicatos Municipais eram anteriores ao FUNDEF, a política de municipais da APP-Sindicato, que se manifesta no caso de Colombo, pode reforçar nossa hipótese. Vamos deixá-la um pouco mais compreensível. A priori, nada impediria, do ponto de vista político ou legal, que a APP-Sindicato organizasse a ação de sua Secretaria de Municipais e impulsionasse as ações 
nos municípios sem Sindicatos Municipais através de algumas câmaras regionais de negociações. Ao contrário, a necessidade da constituição dos Conselhos para se acessar os financiamentos, a partir de uma legislação nacional, formatou um espaço institucional municipal que parece induzir as decisões das direções sindicais. Ainda que se necessitem investigações mais profundas, não nos parece simples coincidência a contemporaneidade entre o nascimento dos CACS e a fundação da Secretaria de Municipais da APP-Sindicato.

Outra característica sindical brasileira, que também pode estar sendo reforçada neste momento é o processo de fortalecimento e legitimação do ator dirigente sindical, independente de sua base social. Se por um lado, o acesso às informações disponíveis no Conselho, assim como as exigências do debate técnico que ali se trava, qualifica a ação sindical; por outro lado, na disputa interna dos trabalhadores pela liderança de seus movimentos fortalecem-se, para usarmos a linguagem de Bourdieu (1996), as posições dos indivíduos detentores de um maior capital técnico, sobre aqueles que detinham apenas um capital político. Tomizaki (2006) investiga as mudanças de escolaridade e formação técnica na trajetória política de diferentes gerações de dirigentes sindicais metalúrgicos. Entre os dirigentes fundadores dos sindicatos docentes na década de 1980, e as atuais lideranças que ocupam diversos conselhos de políticas públicas, se faz necessário o mesmo tipo de indagação. Também é preciso verificar o quanto esta especialização técnica desvincula a atuação do dirigente sindical frente sua base. Sempre lembrando que cultura sindical brasileira incentiva esta separação.
Por fim, é importante investigar quanto este novo modelo de relações entre servidores e Estado interfere no processo de construção da democracia brasileira. Os relatos recolhidos empiricamente sugerem transformações qualitativas nesta relação:

Era uma lógica espontaneísta. Nós somos os trabalhadores, eles são os patrões. Nós vamos lá e detonamos com eles. Eles digam sim ou não. Nós estamos fazendo nosso papel. Claro que esta lógica continua existindo. Mas a gente qualifica isto. Nós somos os trabalhadores sim, eles são os patrões. Mas as nossas propostas têm que ser qualificadas e têm que ser pautadas por uma realidade financeira. E além das questões corporativas de carreira, salário, condições de trabalho, nós também temos um papel de discutir políticas públicas para educação. Discutir a questão pedagógica na rede municipal (entrevista representante do SISMMAC, 2007).

Curiosamente, em um momento de avanço do pensamento e da prática neoliberal de desmontagem do Estado, de privatização do público e de anulação da política (OLIVEIRA, 1999), a atuação dos servidores em conselhos de fiscalização de políticas públicas pode produzir um cenário de invenção democrática, nos termos de Lefort (1987). Pois, o significado político-sociológico do que está ocorrendo pode ser a redefinição dos padrões do conflito trabalhista. Para falarmos na chave conceitual de Oliveira (1993), uma nova sociabilidade na qual uma relação conflitiva de anulação do outro pode ser substituída por uma relação conflitiva de reconhecimento mútuo. Pode estar se processando, portanto, a abertura para uma contratualidade social entre atores desiguais, o que rompe com a tradição autoritária brasileira.

\section{Referências Bibliográficas}

ALMEIDA, M. H. T. Crise econômica e interesses organizados: o sindicalismo no Brasil dos anos 80. São Paulo: Edusp, 1996a.

ALMEIDA, M. H. T. O corporativismo em declínio? In: DAGNINO, E. (Org.) Os anos 90: política e sociedade no Brasil. São Paulo: Brasiliense, 1996b.

ARAGÃO, J. W. M. O FUNDEF: controle social e gestão democrática. In: Gestão em Ação. Bahia: Programa de Pós-graduação da Faculdade de Educação da UFBA; ISP/UFBA, vol. 6, n. 2, julho-dez. 2003.

ARELARO, L. A municipalização do ensino no Estado de São Paulo. In: OLIVEIRA, Cleiton. et al. Municipalização do ensino no Brasil. Belo Horizonte: Autêntica, 1999. 
BOITO JR., A. O sindicalismo de Estado no Brasil: uma análise crítica da estrutura sindical. São Paulo: Hucitec, 1991.

BOURDIEU, P. Razões práticas: sobre a teoria da ação. Campinas: Papirus, 1996.

CAMARGO, R; MANSANO, R; OLIVERIA, R. Tendências da matrícula no ensino fundamental regular no Brasil. In: OLIVEIRA, C. et al. Municipalização do ensino no Brasil. Belo Horizonte: Autêntica, 1999. CARDOSO, A. M. A década neoliberal e a crise dos sindicatos no Brasil. São Paulo: Boitempo, 2003. COMIN, A. A. A estrutura sindical corporativa. São Paulo: Dissertação de Mestrado, FFLCH, USP, 1995. DAVIES, N. O FUNDEF e o Orçamento da Educação: desvendando a caixa preta. Campinas: Ed. Autores Associados, 1999.

FARENZENA, N. A política de Financiamento da Educação Básica: rumos da legislação brasileira. Porto Alegre: UFRGS, 2006.

FERRAZ, M. Da cidadania salarial à Agência de Desenvolvimento Solidário: O sindicalismo-CUT e os desafios para inventar uma nova cidadania. [tese de doutorado]. São Paulo: Departamento de Sociologia, USP, 2005.

FERRAZ, M. Jornalismo nos sindicatos: da prática à abstração da ação sindical. [dissertação de mestrado]. Curitiba, Departamento de Sociologia, UFPR, 2000.

FITOUSSI, J. P.; ROSANVALLON, P. A nova era das desigualdades. Oieiras: Celta, 1999.

FÓRUM PERMANENTE DE CONTROLE E FISCALIZAÇÃO DO FUNDEF. $2^{a}$ Sessão: material de divulgação. S/I, 2004.

GADOTTI, M. Estado e Sindicalismo Docente no Brasil: Conflito, consenso, pacto ou parceria? Disponível em: http://www.paulofreire.org. 1996. Consultado em julho de 2007.

GOUVEIA, A; SOUZA, A. Revisitando a questão danaturezae da prática dos Conselhos de Acompanhamento e Controle Social - CACS do FUNDEF no Paraná in: SOUZA, D. B. (Org.). Acompanhamento e controle social da educação. São Paulo: Xamã, 2006.

GOUVEIA, A; SOUZA, A. O financiamento da Educação em Municípios da Região Metropolitana de Curitiba/PR/Brasil. In: VII Colóquio Internacional de Geocrítica, 2005, Santiago. Los Agentes Urbanos y Las Políticas sobre la Ciudad. Barcelona: Scripta Nova, v. 1., 2005.

KRAWCZYK, N. R. Em busca de uma nova governabilidade em educação. In: ROSAR, M. F. F.; OLIVEIRA, D. A. O. Tendências Contemporâneas da Administração e Gestão Educacional. Belo Horizonte: Autêntica, 2002.

LEFORT, C. A invenção democrática: os limites do totalitarismo. São Paulo: Brasiliense, 1987.

MONLEVADE, J. C. A formação do magistério no Brasil. Sinpro Educação. Brasília, Sindicato de Professores do Distrito Federal, no. 1, outubro, 1990.

NORONHA, E. O modelo legislado de relações de trabalho no Brasil. In: VI Encontro Nacional de Estudos do Trabalho - anais. São Paulo: ABET, 1999.

NOGUEIRA, A. J. F. M. A liberdade desfigurada. São Paulo: Expressão Popular, 2005.

OLIVEIRA, F. Os direitos do antivalor. Petrópolis: Vozes, 1998.

OLIVEIRA, F. Privatização do público, destituição da fala e anulação da política: o totalitarismo neoliberal. In: OLIVEIRA, F.; PAOLI, M. C. (Orgs.). Os sentidos da democracia Petrópolis: Vozes; Brasília: Nedic, 1999. OLIVEIRA, R. P. Uma dimensão avaliativa do FUNDEF: a desigualdade regional. In: Educar, Curitiba: Editora UFPR, $n^{\circ}$ 22, p. 139-151, 2003.

PINTO, J. M. R. Os números do financiamento da educação no Brasil. Pro-posições, v.16, n³, p.75-86, 2005. PRZEWORSKI, A. Capitalismo e social-democracia. São Paulo: Companhia das Letras, 1989.

RIDENTI, M. Trabalho, Sociedade e os ciclos na história da esquerda brasileira. In: ARAÜJO, S; BRIDI, M; FERRAZ, M O sindicalismo equilibrista: entre o continuísmo e novas práticas. Curitiba: UFPR/ SCHLA, 2006.

SADER, E. Quando novos personagens entraram em cena, 1970-80. Rio de Janeiro: Paz e Terra, 1988. SANTOS, J. M. P. A Municipalização do Ensino no Estado do Paraná: História, herança e desafios. In: 
SOUZA, A e GOUVEIA, A O financiamento da Educação e o FUNDEF no Paraná. Curitiba, UFPR, 2001. TIRAMONTI, G. Sindicalismo docente e reforma educativa na América Latina na década de 1990. PREAL, №. 19, setembro. Disponível em: http://cpdoc.fgv.br/projetos/arq/Preal_Doc19.pdf, 2001, consultado em julho 2007.

TOMIZAKI, K. A. Tornar-se sindicalista: o aprendizado da liderança. In: Silvia Maria de Araújo; Marcos Ferraz. (Org.). Trabalho e Sindicalismo: tempo de incertezas. São Paulo: LTr Editora Ltda., 2006.

VÉRAS DE OLIVEIRA, R. Sindicalismo e democracia no Brasil: atualizações de novo sindicalismo ao sindicato cidadão. São Paulo: Tese de Doutorado, Faculdade de Filosofia, Letras e Ciências Humanas, USP, 2002.

VERHINE, R. Levantamento do custo-aluno-ano em escolas de Educação Básica que oferecem condições de oferta para um ensino de qualidade, Brasília: INEP, 2006.

VIANNA, W. L. J. A judicialização da política e das relações sociais no Brasil. Rio de Janeiro: REVAN, 1999. XAVIER, A. C.; MARQUES, A. E. S. Custo direto de funcionamento das escolas públicas de $1^{\circ} \mathrm{grau}$. Brasília, SEPS, Acordo MEC-BIRD, 1986. 